\title{
Estudos quantitativos em educação
}

Bernardete A. Gatti

Fundação Carlos Chagas

\section{Resumo}

0 artigo trata de estudos em educação, realizados no Brasil nas últimas três décadas, utilizando abordagens quantitativas. Para a seleção dos trabalhos a serem tratados fez-se um levantamento em todos os números publicados de 1970 para cá dos seguintes periódicos: Revista Brasileira de Estudos Pedagógicos (lnep/ MEC), Cadernos de Pesquisa (Fundação Carlos Chagas), Educação e Realidade (UFRS), Educação e Sociedade (Cedes/Unicamp), Revista Brasileira de Educação (ANPEd), Estudos em Avaliação Educacional (Fundação Carlos Chagas), Ensaio (Fundação Cesgranrio). Algumas fontes bibliográficas foram consultadas na busca de outros estudos. Ressalta-se a importância de perspectivas teóricas para o delineamento e desenvolvimento dos estudos, que devem ser colocados no contexto de uma reflexão educacional e de problematização, bem como, assinala a necessidade de adequação das escolhas dos tipos de análise a serem empregados. Discute a pouca tradição de realização de trabalhos em educação com as metodologias quantitativas no Brasil e o possível papel da quantificação na pesquisa educacional. Mostra algumas contribuições desses trabalhos à reflexão no campo da Educação, bem como para a fundamentação de algumas perspectivas críticas. Essas contribuições foram tratadas por temas, a saber: analfabetismo, percurso escolar e fracasso escolar; fluxo escolar/análise de coortes; letramento; políticas e educação básica; financiamento da educação/municipalização; fatores sociais e educação; jovens e educação; avaliação educacional; temas variados.

\section{Palavras Chave}

Pesquisa educacional - Métodos quantitativos - Estatísticas Demografia.

Correspondencia: 


\title{
Quantitative studies in education
}

Bernardete A. Gatti

Fundação Carlos Chagas

\begin{abstract}
The article refers to studies in education carried out in Brazil during the last three decades using quantitative approaches. The selection of the works to be examined was based on a survey of all issues published since 1970 by the following journals: Revista Brasileira de Estudos Pedagógicos (Inep/MEC), Cadernos de Pesquisa (Fundação Carlos Chagas), Educação e Realidade (UFRS), Educação e Sociedade (Cedes/Unicamp), Revista Brasileira de Educação (ANPEd), Estudos em Avaliação Educacional (Fundação Carlos Chagas), and Ensaio (Fundação Cesgranrio). Some bibliographical sources were consulted in the search for other studies. The text highlights the importance of theoretical perspectives for the outlining and development of the studies, which should be put in the context of a reflection on education and of problematization. It also points to the need for adjusting the choices of types of analyses used. The work discusses the weak Brazilian tradition of carrying out quantitative studies in education, and the possible role of quantification in educational research. It shows some contributions from quantitative studies to the reflection in the field of education, and also for the basis of some critical perspectives. Those contributions were treated according to some themes, namely: illiteracy, schooling path and school failure; school flux/cutoff analysis; literacy; policies and basic education; financing of education/municipalization; social factors and education; youth and education; educational evaluation; assorted themes.
\end{abstract}

\section{Keywords}

Educational research - Quantitative methods - Statistics Demography.

Contact:

Bernardete A. Gatti

Av. Prof. Francisco Morato, 1565

05513-900 - São Paulo - SP

e-mail: gatti@fcc.org.br 
Atualmente, na área da pesquisa educacional, excluindo análises de dados de avaliações de rendimento escolar realizadas em alguns sistemas educacionais no Brasil, poucos estudos empregam metodologias quantitativas. Há mais de duas décadas que na formação de educadores e de mestres e doutores em educação não se contemplam estudos disciplinares sobre esses métodos. No entanto, há problemas educacionais que para sua contextualização e compreensão necessitam ser qualificados através de dados quantitativos. Por exemplo, como compreender a questão do analfabetismo no Brasil, e discutir políticas em relação a esse problema, sem ter dados sobre seu volume e a sua distribuição segundo algumas variáveis, como gênero, idade, condição socioeconômica, região geográfica, cidade-meio rural, etc. Os números aqui se tornam muito importantes $\mathrm{e}$ suas relações também. No entanto, o uso das bases de dados existentes sobre educação é muito pequeno pela dificuldade dos educadores em lidar com dados demográficos e com medidas de um modo geral. Estudos que utilizam mensurações também são poucos. Essa dificuldade no uso de dados numéricos na pesquisa educacional rebate de outro lado na dificuldade de leitura crítica, consciente, dos trabalhos que os utilizam, o que gera na área educacional dois comportamentos típicos: ou se acredita piamente em qualquer dado citado (muitas vezes dependendo de quem cita - argumento de autoridade), ou se rejeita qualquer dado traduzido em número por razões ideológicas reificadas, a priori.

No emprego dos métodos quantitativos precisamos considerar dois aspectos, como ponto de partida: primeiro, que os números, freqüências, medidas, têm algumas propriedades que delimitam as operações que se podem fazer com eles, e que deixam claro seu alcance; segundo, que as boas análises dependem de boas perguntas que o pesquisador venha a fazer, ou seja, da qualidade teórica e da perspectiva epistêmica na abordagem do problema, as quais guiam as análises e as interpretações.
Sem considerar estas condições como ponto de partida, de um lado, corre-se o risco de usar certos tratamentos estatísticos indevidamente, e, de outro, de não se obter interpretações qualitativamente significativas a partir das análises numéricas. Em si, tabelas, indicadores, testes de significância, etc., nada dizem. 0 significado dos resultados é dado pelo pesquisador em função de seu estofo teórico.

Os métodos de análise de dados que se traduzem por números podem ser muito úteis na compreensão de diversos problemas educacionais. Mais ainda, a combinação deste tipo de dados com dados oriundos de metodologias qualitativas, podem vir a enriquecer a compreensão de eventos, fatos, processos. As duas abordagens demandam, no entanto, o esforço de reflexão do pesquisador para dar sentido ao material levantado e analisado.

\section{Sem tradição sólida}

Comum é encontrarmos a afirmação de que até meados do século passado predominavam no Brasil os estudos de natureza quantitativa, batizados de tecnicistas ou, mais inadequadamente, positivistas. No entanto, estudos publicados nos inícios dos anos 1970 (Gouveia, 1980; Di Dio,1974) nos mostram, primeiro, que a pesquisa em educação era muito escassa e mesmo incipiente até então; e, segundo, que além disso, dos estudos levantados pelos autores citados, $71 \%$ não eram estudos que utilizavam dados quantitativos e, dentre os que os utilizavam, a maioria empregava apenas análise descritiva de tabelas de freqüências, alguns poucos correlações e raríssimos estudos empregavam análise multidimensional. Di Dio (1974, p. 520) assim se expressa:

1. A esmagadora maioria das investigações são históricas ou estudos descritivos, levantamentos e outros enfoques não-experimentais. 2. 0 instrumento de medida preferido é o questionário.

3. Quando são empregadas técnicas estatís- 
ticas, trata-se usualmente de percentagens e coeficientes de correlação.

0 uso de dados quantitativos na pesquisa educacional no Brasil nunca teve, pois, uma tradição sólida, ou uma utilização mais ampla. Isto dificultou, e dificulta, o uso desses instrumentais analíticos de modo mais consistente, bem como dificulta a construção de uma perspectiva mais fundamentada e crítica sobre o que eles podem ou não podem nos oferecer; dificulta ainda a construção de uma perspectiva consistente face aos limites desses métodos, limites que também existem nas metodologias ditas qualitativas os quais, em geral, não têm sido também considerados. De outro lado, dificulta a leitura crítica e contextuada quando dados quantitativos são trazidos à discussão, seja nos âmbitos acadêmicos, seja em âmbito público.

Devemos considerar também que, muitos dos estudos quantitativos em educação, especialmente os que se utilizam de técnicas de análise mais sofisticadas, mais flexíveis e mais robustas, não são realizados por educadores mas por pesquisadores de outras áreas que se debruçam sobre o objeto educação (economistas, físicos, estatísticos, sociólogos, psicólogos, etc.). Com isto, interpretações e teorizações nem sempre incorporam as discussões em pauta no campo das reflexões sobre a educação.

\section{A abordagem quantitativa: significado e condições}

As colocações de Falcão e Régnier (2000, p. 232) podem pautar nossa compreensão do papel da quantificação na pesquisa educacional. Esses autores postulam que a análise de dados quantitativos constitui-se em um trabalho que propicia que "a informação que não pode ser diretamente visualizada a partir de uma massa de dados poderá sê-lo se tais dados sofrerem algum tipo de transformação que permita uma observação de um outro ponto de vista". Complementam que "a quantificação abrange um conjunto de procedimentos, técnicas e algoritmos destinados a auxiliar o pesquisador a extrair de seus dados subsídios para responder à(s) pergunta(s) que o mesmo estabeleceu como objetivo(s) de seu trabalho". 0 grifo dessas duas palavras pelos autores citados é muito importantes porque nos lembram que os métodos quantitativos de análise são recursos para o pesquisador, o qual deve saber lidar com eles em seu contexto de reflexão (num certo sentido deve dominá-los) e, não, submeter-se cegamente a eles, entendendo que o tratamento desses dados por meio de indicadores, testes de inferência, etc. oferecem indícios sobre as questões tratadas, não verdades; que fazem aflorar semelhanças, proximidades ou plausibilidades, não certezas.

0 domínio de que falamos demanda conhecimento dos pressupostos que sustentam cada técnica de análise quantitativa empregada e de seus conseqüentes. Pressupõe um conhecimento do contexto em que os dados foram produzidos e de sua forma de medida e de coleta. Pressupõe um conhecimento amplo e aprofundado da área em que os problemas estudados se situam. Pressupõe, pois, o dominio de teorizações e o conhecimento de seus contornos epistêmicos. Este domínio permite escapar ao uso mecânico de técnicas de análise quantitativa, permite ainda detectar os maus usos dessas técnicas e as distorções de análises.

Há diversas formas de se obter quantificações, dependendo da natureza do objeto, dos objetivos do investigador e do instrumento de coleta. Podemos, grosso modo, distinguir três tipos de dados: categóricos, ordenados e métricos. Para cada um deles há possibilidades de tratamentos específicos. Os dados categoriais são aqueles que apenas podemos colocar em classificações (classes) e verificar sua freqüência nas classes. Exemplo simples deste tipo de dado é a contagem de pessoas conforme seu sexo nas categorias masculino e feminino; a leitura preferida escolhida: livros ou revistas ou jornal ou nenhum; o último nível escolar freqüentado: 
nenhum/fundamental/médio/superior. Categorizações permitem agrupamento segundo alguma característica, discriminando um agrupamento do outro. Podem-se cruzar categorizações obtendo maior detalhamento da informação: sexo x último nível escolar freqüentado; ou sexo $x$ último nível escolar freqüentado $x$ leitura preferida. Os dados são chamados de ordenados quando estão numa forma que mostra sua posição relativa segundo alguma característica, mas que não há associação de um valor numérico para essa característica, nem um intervalo regular entre uma posição e outra. Um exemplo é a ordem de chegada de carros em uma corrida: primeiro, segundo, terceiro, etc., ou a ordenação de alunos por um professor apenas de acordo com a sua opinião sobre seu desempenho, do melhor ao pior: o primeiro colocado, o segundo, o terceiro, etc. 0 terceiro tipo de dado - métrico - consiste de observações relativas a características que podem ser mensuradas e expressas numa escala numérica: os graus da temperatura; notas em uma escala definida. Cada tipo de dado implica tipos diferentes de tratamento estatístico possíveis. Lembramos que todas as medidas são arbitradas, criadas, inventadas, e não podem ser tomadas como sendo a própria natureza das coisas; isto também se aplica às categorias dos estudos de análise de conteúdo e outras análises dos modelos qualitativos. 0 que se procura ao criar uma tradução numérica ou categorial de fatos, eventos, fenômenos, é que esta tradução tenha algum grau de validade racional, teórica, no confronto com a dinâmica observável dos fenômenos.

\section{Visitando alguns trabalhos}

Procuramos trazer para comentar neste artigo alguns trabalhos realizados com abordagens quantitativas, representativos na discussão educacional nos últimos trinta anos, bem como representativos de formas de análise diversificadas. Tentaremos mostrar como dados se compõem com teoria e interpretações qua- litativas e que determinadas questões demandam dados numéricos e suas técnicas de análise. Para a seleção dos trabalhos fizemos um levantamento exaustivo em todos os números publicados de 1970 para cá dos seguintes periódicos: Revista Brasileira de Estudos Pedagógicos (Inep/MEC); Cadernos de Pesquisa (Fundação Carlos Chagas); Educação e Realidade (UFRS); Educação e Sociedade (Cedes/ Unicamp); Revista Brasileira de Educação (ANPEd); Estudos em Avaliação Educacional (Fundação Carlos Chagas); Ensaio (Fundação Cesgranrio). Procedemos a um levantamento de fontes bibliográficas indexadas para detectar livros ou relatórios contendo esse tipo de abordagem. Não nos debruçamos sobre dissertações de mestrado ou teses. Entre os trabalhos encontrados selecionamos os que mais aparecem referenciados em determinado tema, ou que se constituiram em foco de debate. Certamente algumas pesquisas importantes ficarão fora da presente exposição, mas uma escolha se fez necessária. Apresentaremos os trabalhos por sub-conjuntos temáticos.

\section{Analfabetismo, percurso escolar e fracasso escolar}

Muitos dos estudos sobre os problemas de fluxo escolar, analfabetismo, fracasso escolar são de natureza demográfica, ou seja, trabalham com massas de dados populacionais, de sistemas educacionais ou sub-sistemas. Esses estudos permitem: 1. análises do estado, da situação geral, ou associada a determinados fatores, em relação a problemas sociais/educacionais, pelo agrupamento de dados, pelo cálculo de taxas ou indicadores simples ou mais complexos; 2 . análises de movimento, que propiciam perspectivas sobre ocorrências ao longo de um certo período de tempo (um ano, vários anos, décadas, etc.) evidenciando a dinâmica dos eventos.

Nos estudos demográficos em educação há tempos se destacam os trabalhos de Alceu R. Ferrari, não só pelos tratamentos que reali- 
zou e realiza com dados censitários abordando problemas do analfabetismo, dos fluxos escolares, como pelas suas preocupações metodológicas e de teoria educacional. Ferrari (1979, p. 253-266) em artigo publicado pela revista Educação e Realidade da Faculdade de Educação da Universidade Federal do Rio Grande do Sul, em que trata dos usos de estatísticas educacionais dos censos e dos registros escolares, deixa clara sua preocupação em mostrar as diversas possibilidades de utilização das estatísticas educacionais tanto descritiva como explicativamente, seu alcance e seus limites, considerando a "importância de se evitar o empirismo, o maior risco, sem dúvida, na utilização de fontes estatísticas", como também considerando que a "mediação teórica é indispensável para se passar do dado para o indicador. Não bastam dados, uma calculadora e um operador". Citando Solari (1963, p. 61) lembra: "Todo indicador supõe um ou mais dados elaborados de maneira refinada ou tosca, porém eles não bastam para se construir um indicador, já que se requer sua inserção em uma teoria”. Selecionamos três trabalhos de Ferrari (1985; 1988 ; 2002) realizados em momentos diferentes de nossa história educacional, que trouxeram dados e análises que são fontes seguras de inspiração tanto para a reflexão crítica sobre os sistemas educacionais como para a proposição de ações educacionais. No artigo "Analfabetismo no Brasil: tendência secular e avanços recentes" (Ferrari, 1985, p. 35-49) confronta dados das PNADs 1977 e 1982 (Pesquisa Domiciliar por Amostragem de Domicílios) e do Censo Demográfico de 1980 com as experiências do Mobral relativamente ao declínio dos índices de analfabetismo no Brasil na década de 1970. Analisa a tendência secular (1872 a 1980) dos índices de analfabetismo para o Brasil e algumas regiões, levantando a questão das origens históricas das desigualdades educacionais regionais. Com base em comparação de dados de diversas naturezas e indicadores procura lançar luz sobre o processo de produção do analfabetismo e sobre as relações entre analfabetismo e ensino fundamental. Conclui questionando as políticas oficiais em suas contradições, mostrando ainda como a escola produz o analfabetismo por meio do processo de exclusão, processo este que engloba tanto aqueles que são excluídos sem sequer chegar a ser admitidos a ela na idade de escolarização obrigatória, como os que, tendo sido admitidos, são depois excluídos no próprio processo de ensino pela reprovação e a repetência.

A exclusão praticada no processo de alfabetização, através da reprovação e repetência, alimenta, no momento seguinte, através do que eufemísticamente se denomina de evasão escolar, o contingente dos já excluídos do processo (Ferrari, 1985, p. 49)

No texto de 1988 (p. 55-74) publicado pela RBEP Alceu Ferrari estuda a evolução da matrícula e dos índices de atendimento préescolar no Brasil, entre 1968 e 1986, confrontando a participação do setor público e do privado nessa evolução. Usando dados censitários brutos, taxas de escolarização, taxas de incremento e dados de renda familiar, discute a relação público/privado, as políticas do Conselho Federal de Educação no setor, questões de renda e pré-escola e a questão da qualidade do atendimento pré-escolar. Nas conclusões ressalta que os resultados "casam muito bem com o próprio projeto social do período da ditadura militar - projeto autoritário, seletivo, excludente. Não há nada nas análises feitas que indique uma diminuição das desigualdades escolares e sociais através da educação pré-escolar oferecida pelos poderes públicos”. Os índices e as relações encontradas mostram uma realidade que fica muito distante "das intenções ou propósitos enunciados pelos formuladores da política educacional”. (Ferrari, 1988, p. 72) 0 artigo de Ferrari (2002, p. 21 47) publicado pela revista Educação e Sociedade, trata do analfabetismo e dos niveis de letramento no Brasil. Faz uma grande síntese histórica de dados, a partir da discussão da 
emergência do analfabetismo como problema político no final do período imperial e das mudanças conceituais quanto à caracterização do analfabetismo, o que gera problemas de comparabilidade. A partir disso, estuda as tendências de longo prazo, desde o primeiro censo de 1872 até o censo de 2000, e, com base neste censo, classifica a população em diferentes níveis de letramento. Por um lado, os dados trabalhados mostram a persistência do analfabetismo no país. Verifica-se pelas tabelas e gráficos que, se houve queda progressiva da taxa de analfabetismo no Brasil, por outro verifica-se o aumento continuado do número absoluto de analfabetos até 1980 com queda nesse número até o ano 2000 , porém, restando ainda muitos milhões de brasileiros "marcados com o estigma do analfabetismo, essa forma extrema de exclusão educacional, geralmente secundada por outras formas de exclusão social". Quanto aos níveis de letramento mostra que dois terços da população de 15 anos ou mais (71 milhões) estão entre a categoria "sem instrução e menos de um ano de estudo" e "até 7 anos de estudo", ou seja, sem terminar o ensino fundamental. Isto dá uma dimensão do "tamanho do desafio posto à educação nos próximos anos (ou décadas?)”. Assim, pensando política educacional, "os resultados do estudo obrigam a questionar fortemente o princípio e a prática de, a título de priorização da educação fundamental na 'idade própria', relegar-se a segundo plano a educação de jovens e adultos e a educação infantil”. Lembra então que, “o não acesso de muitas crianças ainda à educação infantil está constituindo-se rapidamente em fator de diferenciação e discriminação no processo de escolarização" (Ferrari, 2000, p. 44).

Ainda podemos destacar estudo sobre os indicadores de analfabetismo de Pinto et al. (2000, p. 511-524), publicado na RBEP/Inep, analisando fatores associados ao analfabetismo, a partir do Censo de 2000, detalhando o analfabetismo por município, gênero, idade e renda, tendo como contexto de análise as políticas e programas de erradicação do analfabetis- mo e a questão dos alfabetizadores. Em função do grande número de programas para superação do analfabetismo, e sua descontinuidade, é preciso pensar em otimizar recursos e qualificar melhor os alfabetizadores. Concluem:

De qualquer forma, uma coisa é certa: sempre há e sempre houve disposição da população para se engajar nos programas de alfabetização; o que faltou muitas vezes foram programas de qualidade, claramente delineados para seus diferentes perfis, e com o nível de profissionalização que se espera de qualquer atividade. Nesta área, improvisação geralmente redunda em fracasso[...] (Pinto et al., 2000, p. 523)

\section{Fluxo escolar/análise de coortes: outra metodologia}

Em 1993 Sérgio C. Ribeiro publica artigo confrontando as análises quantitativas do MEC com as feitas por um modelo alternativo - Profluxo (Fletcher; Ribeiro, 1989) - com o qual elabora um novo cenário do fluxo de alunos no ensino fundamental no Brasil. Suas análises mostram com clareza os problemas da repetência no âmbito escolar: "Os graduados levam (no ensino fundamental) em média 11,4 anos freqüentando a escola de $1^{\circ} \mathrm{grau}$, o que corresponde a um acúmulo de mais de três repetências por graduado" (Ribeiro, 1993, p. 67). As curvas de fluxo "além de mostrar a ineficiência do sistema, reforçam também a interpretação sobre a persistência de nossos alunos em sua determinação de se educar". Analisa as diversas formas de repetência praticadas no cotidiano do sistema e suas conseqüências (em dados), estuda essa questão segundo índices de renda e grupos populacionais diferentes, complementando suas análises com comparação de dados do desempenho de alunos de 13 anos de idade em matemática, com o produto nacional bruto (PNB) per capita e gastos com educação. lsso o leva a tratar do custo aluno/ano no sistema público de ensino 
fundamental. Avança no texto algumas conclusões, como: “A idéia de que a repetência é boa para o aluno e sinal de bom ensino na escola está baseada num dos muitos mitos equivocados. Observa-se que a probabilidade de um aluno repetente ser aprovado é quase a metade da probabilidade de aprovação de um aluno novo na série..... Com este dado afirma que "a repetência é, em si mesma, uma das principais causas da repetência”, completando:

É claro que nessa nossa "pedagogia da repetência”, a ameaça de reprovação constitui o principal mecanismo de pressão ou 'motivação' para que os alunos estudem. Esse mecanismo revela a cultura autoritária e repressiva de nossa sociedade, e é difícil de ser substituído por outros tipos de motivação, de natureza positiva. (Ribeiro, 1993, p. 72)

Ribeiro encerra seu texto discutindo um novo modelo de gestão e financiamento da escola pública e o papel do Estado. Este trabalho, sem dúvida, causou impacto na discussão do problema da repetência nos sistemas de ensino.

\section{A questão do letramento: uma discussão recente}

Do ponto de vista de análises que utilizam dados quantificados, destacamos aqui os trabalhos realizados por pesquisadoras da ONG Ação Educativa. Ribeiro (1998, 2003) estudando analfabetismo funcional no âmbito de um projeto internacional comparado, coordenado pela OREALC/Unesco, aplicou em São Paulo, a uma amostra representativa de mil jovens e adultos, da população de 15 a 54 anos de idade, um teste de leitura e um questionário, e, com uma sub-amostra de 26 casos, realizaramse entrevistas em profundidade, propondo-se também tarefas simuladas de leitura e escrita para serem realizadas em interação com as entrevistadoras. 0 delineamento da pesquisa, os instrumentos e as análises fundamentaram-se em discussões teóricas sobre o conceito de alfabetismo/analfabetismo funcional e seu papel social, havendo um cuidadoso tratamento do estado do campo teórico. Isto conduziu a algumas definições metodológicas que nortearam o trabalho de campo e as análises.

Considerando que toda a população pesquisada participa de uma sociedade caracterizada pelo alfabetismo, ou seja, pela ampla utilização da linguagem escrita em várias esferas do sistema social, passam a interessar as diferentes atitudes em relação a esses contextos e a essa tradição cultural que possam estar associadas a diferentes graus e tipos de habilidade e uso da linguagem escrita. (Ribeiro, 1998, p. 7)

0 estudo abordou ainda as relações do alfabetismo com a escolarização. 0 conjunto da amostra foi caracterizado segundo niveis de habilidades evidenciados no teste, cruzando-se estes niveis com alguns fatores explicativos. As análises ainda levaram à distinção de quatro domínios relacionados ao alfabetismo: atitudes com relação à expressão da subjetividade; atitudes com relação à informação; atitudes com relação ao planejamento e controle de procedimentos; atitudes com relação à aprendizagem. Feitas as análises estatísticas, entre elas análises multivariadas, e discutidos os resultados à luz do referencial adotado, Ribeiro faz uma reflexão crítica detalhada sobre as implicações político-pedagógicas em função do que esse conjunto de dados evidenciou. Contesta a imagem da alfabetização "como uma vacina" que erradicaria para sempre o analfabetismo; os contextos de vida podem complementar/extinguir essas habilidade. Processos fugazes não resolvem o problema.

As políticas de intervenção nesse campo devem fundar-se numa visão integrada dos processos de aquisição, manutenção e desenvolvimento das habilidades de leitura e escrita entre crianças, jovens e adultos, no trabalho, na escola, na família, nas organizações da coletividade, esta- 
belecendo nexos entre a educação básica e a educação continuada. (Ribeiro, 1998, p. 11)

É importante garantir um patamar comum de habilidades e atitudes com relação à linguagem escrita, pois isto é

um fator fundamental de coesão nas sociedades complexas, de igualdade de oportunidades e de ampliação de possibilidades comunicativas, graças às quais cada pessoa se apropria e se enriquece com a diversidade que é própria da cultura. (Ribeiro, p. 14)

Uma pesquisa extensiva ao Brasil, nesta mesma direção, foi realizada em 2001 e publicada sob o título "Letramento no Brasil: alguns resultados do indicador nacional de alfabetismo funcional (Ribeiro; Vóvio; Moura, 2002 , p. 49-70). A amostra representativa nacional abrangeu pessoas de 15 a 64 anos, e os dados foram analisados levando em conta níveis obtidos em habilidade de leitura e escrita, por anos de estudo, regiões, sub-grupos da população, renda, sexo, idade, gosto por ler. Os dados da pesquisa sobre letramento no Brasil mostrou com clareza nichos bem problemáticos quanto ao uso da leitura e escrita. Pelos números e tratamentos multivariados vê-se que

um contingente significativo utiliza as habilidades de leitura e escrita em contextos restritos e, conseqüentemente, demonstra habilidades restritas no teste de leitura... A pesquisa revela como os déficits educacionais se traduzem em desigualdades quanto ao acesso a vários bens culturais, oportunidades de trabalho e desenvolvimento pessoal que caracterizam as sociedades letradas. (Ribeiro, 1998, p. 68)

\section{Políticas de educação básica}

Um dos estudos que causou impacto nas análises de políticas educacionais para 0 ensino fundamental (à época, ensino de $1^{\circ}$ e $2^{\circ}$ graus), nos anos 1980 , foi o realizado por
Barretto et al. (1979, p. 21-40). A pesquisa foi realizada nos anos finais da ditadura militar, numa perspectiva crítica, discutindo e contrapondo dados do sistema de ensino aos objetivos colocados nos documentos oficiais. Além de analisar taxas de escolarização no ensino fundamental, sob as condições de vários fatores, trazem dados da dinâmica evolutiva da pirâmide educacional, agregando dados sobre a préescola, o ensino supletivo e a orientação curricular vigente então. A perspectiva em que as autoras se colocam, e que orientou o tratamento dos dados, assim se traduzia:

A análise da política educacional não pode prescindir do confronto do que é declarado nos pressupostos e metas que as orientam, com os dados a respeito dos resultados alcançados. [...] Desse modo, a dimensão do declarado - expressa pelos planos, programas e projetos de ação - passa a ser entendida em seu caráter político, isto é, como produtos da negociação entre interesses diferentes ou até mesmo antagônicos, tendo em vista obter certo grau de consenso acerca dos fins e dos meios da educação, consenso este que, mesmo que provisório, é necessário como apoio à ação político-educacional. (Ribeiro, 1998, p. 21).

A alocação de recursos tem papel importante aqui, visto que pensar a democratização do ensino não basta, é preciso que as ações efetivamente realizadas sejam democratizadoras. As análises, os contrapontos de dados efetivados, a perspectiva de fundo que orientou as autoras levam-nas a afirmar que "a escola é muito mais determinada do que determinante em suas relações com o meio social." (Ribeiro, p. 36) Mas, isto não pode ser um álibi cômodo para os gestores e componentes do sistema. Se por um lado as autoras põem em questão "o pedagogismo ingênuo que supõe ser a educação o principal elemento propulsor da superação da pobreza”, por outro colocam a tarefa inadiável, nessa tomada de consciência, de "encontrar e viabilizar alternativas de ação que permitam à 
escola ocupar esse espaço que lhe é próprio [...] Nesse caminho passar-se-á pelo pedagógico". Não esquecendo que "mudanças qualitativas e prioridades quantitativas são integrantes de uma mesma unidade [...]" e que "uma escola que se modifica para ir de [sic] encontro às necessidades da maioria, deverá necessariamente expandir-se quantitativamente no mesmo sentido" (Ribeiro, 1998, p. 36). Esse trabalho gerou vários outros e teve penetração não apenas nos âmbitos acadêmicos, mas nos âmbitos da administração pública da educação, gerando em ambos os meios novas formas de tratar a questão da democratização do ensino.

$\mathrm{Na}$ linha das análises de inspiração demográfica, indispensáveis para uma visão macro das situações educacionais, com dados que permitiram panoramas sobre o atendimento de crianças de 0 a 6 anos, encontramos os trabalhos de Rosemberg (1989; 1991; 1992; $1996 ; 1999 ; 2001)$. Situa seus dados face a idéias difundidas e políticas implementadas. Seus trabalhos tiveram ressonância seja em Comissões Parlamentares, seja em órgãos executivos da área da Educação, seja em órgãos da sociedade civil, não só no Brasil como em nível internacional. Entre seus trabalhos destacamos o artigo "Educação infantil, classe, raça e gênero (Rosemberg, 1996, p. 58-65). Usa, neste texto, tabulações especiais de PNAD's para situar seu problema no complexo de variáveis que o compõem, analisando também, através de várias outras fontes, dados sobre a escolaridade de trabalhadores(as) de educação infantil, em diversas modalidades de estabelecimento e pelas suas várias denominações profissionais. Com base nos achados numéricos e agregando vários estudos à sua discussão, inclusive sobre as tendências de políticas de educação infantil no Brasil e em outros países, mostra que nestes países havia um movimento de requalificação da educação infantil, após um processo de expansão, o que não se verifica no Brasil.

A expansão desordenada, caótica e, principalmente, a permanência de trajetórias duplas, tri- plas ou quádruplas em educação infantil - creches públicas, creches conveniadas, pré-escolas públicas e conveniadas -, geralmente abrem possibilidades ao oferecimento simultâneo de serviços com qualidade extremamente desigual. É esta desigualdade no custeio/qualidade que penaliza crianças pobres e negras de diferentes formas, inclusive esta que denominei de morte educacional anunciada [...] 0 caminho que nos parece mais adequado neste momento para superar este intrincado jogo de subordinação de classe, raça, gênero e idade que vem prejudicando as crianças através da educação infantil seria o da formação e qualificação da trabalhadora que lida diretamente com a criança. (Rosemberg, 1996, p. 64)

Continuando essa discussão, Rosemberg publica em 1999 um novo estudo sobre a expansão da educação infantil e os processos de exclusão. Trabalhando com diferentes indicadores construídos para várias décadas - taxas de escolarização, IDH, etc. - considerando idade, cor, rendimento familiar, sexo, situação urbana ou rural, região. Parte de dados do IBGE, PNAD's, SEEC/MEC, PNUD/IPEA, faz análises de movimento da população inserida/não inserida na educação infantil, delineia perfis das crianças, calcula correlações entre indicadores sociorraciais, faz testes de significância. Mostra com clareza como complexas relações de elementos socioeconômicos, culturais e políticos constroem a exclusão de camadas populacionais que ficam à margem do processo de mobilidade social:

as análises apontam que houve um exacerbamento desse processo no bojo da implantação de uma política educacional para todos, baseada no argumento da equalização de oportunidades: para os pobres (compensação de carência), e, para as mulheres (a educação infantil como alternativa de guarda do filho, permitindo o trabalho materno). E, o paradoxal é que, em todos os estados que implantaram esse modelo de educação infantil a baixo investimento, as constitui- 
ções estaduais estampam pronunciamentos antiracistas e anti-sexistas no capítulo da educação.” (Rosemberg, 1999, p. 34)

Quanto ao ensino médio as referências e estudos são em menor número do que os relativos ao ensino fundamental e à educação infantil. Trabalho recente de Franco; Zibas (1999) traz uma detalhada análise de indicadores para o final do século XX. Dissecam a questão analisando a evolução das matrículas nesse nível com comparações populacionais, os municípios ofertantes/não ofertantes, por região, funções docentes e formação, dependência administrativa, turno escolar, faixa etária, distorção série/idade, sexo, aprovação/reprovação, habilitações. Ao longo do texto discutem os dados à luz de discussões de políticas em educação, da legislação proposta. Partem da idéia de que,

Nesse cenário de grandes inovações, é necessário, mais do que nunca, manter sempre atualizados os indicadores quantitativos, submetendo-os constantemente a análises que tracem o panorama evolutivo do Ensino Médio, construindo diagnósticos e prognósticos que orientem novas ações dos órgãos centrais, seja para reforçar diretrizes já traçadas, seja para corrigir efeitos não desejados. (Franco; Zibas, 1999, p. 3)

Ao finalizarem seu texto, pontuam:

As análises realizadas permitem concluir que o aumento considerável das matrículas no Ensino Médio, principalmente nas redes estaduais, está exigindo o aprimoramento de estudos projetivos para que se possa aquilatar o ritmo de crescimento da demanda. A urgência de maior investimento - financeiro e técnico - nas redes estaduais é o imperativo mais contundente que se deduz a partir das estatísticas detalhadas neste trabalho. Além disso, a predominância de cursos noturnos, que deve, infelizmente, permanecer por muito tempo ainda, indica a necessidade de que o Ensino Médio se reestruture para o atendimento das peculiaridades do trabalhador-estudante. (op cit., p. 65).

\section{Financiamento da Educação/ \\ Municipalização}

Ao analisarmos os estudos sobre financiamento da educação verificamos que teoricamente se acham associados às discussões de políticas. Estes estudos dependem de exame detalhado de dados quantitativos, com domínio da contabilidade pública e sua legislação. Esses dados não prescindem de tratamentos adequados pois, em bruto, pouco informam. Nessa área, infelizmente, poucos estudos analíticos são feitos. Podemos citar, como referência, alguns trabalhos clássicos, outros mais recentes. 0 texto de Melchior (1980), sobre financiamento da educação no Brasil numa perspectiva democrática, foi marcante. Melchior analisou aspectos do financiamento da educação, com dados reprocessados e reorganizados para uma análise mais consistente da questão, em geral discutida sem grandes apoios em dados fidedignos. Trabalhou com uma visão integrada de aspectos políticos, econômicos e sociais, chegando a propor sugestões a curto, médio e longo prazos. Em 1982, Paro publica estudo dos custos diretos do aluno do ensino público do estado de São Paulo. Pesquisando, por um sistema amostral nas escolas, e com a discussão de alguns conceitos relativos aos tipos de dados a serem colhidos, expõe a metodologia de cálculo a que chegou. Com isso estuda o custo/aluno/ano segundo os tipos de escola, as regiões, as classes de renda per capita, os níveis de carência, os níveis de hierarquia funcional, o número de alunos e número de turnos, levantando questões relevantes para a discussão do financiamento da escola. Gomes Netto (1993) estudou a relação entre investimentos em educação - livro escolar, material didático, condições físicas da escola - e melhoria da eficiência, constatando impacto positivo na 
trajetória escolar, associado a esses investimentos. Jacques Velloso (1985; 1987a-b; 2000) e Velloso et al. (1992) desenvolveram vários trabalhos no tema, sendo referência na área, tratando de aspectos diversos dos recursos para o ensino e as políticas educacionais. A Revista Brasileira de Estudos Pedagógicos em seus números 200/201/202 (v. 82) de 2001 publicou o relatório do Grupo de Trabalho criado pelo ministro Cristóvam Buarque (a data da revista não corresponde à data de sua real publicação que foi em 2003) sobre financiamento da educação. Analisam-se os gastos feitos pelos diferentes níveis de governo, como também pelas famílias, discutindo-se os custos estimados de uma escola de qualidade e o impacto do Fundo (a criar) de Manutenção e Desenvolvimento da Educação Básica e da implementação das metas estabelecidas no Plano Nacional de Educação (PNE). Com a análise dos dados e os cálculos estimados conclui-se que os gastos públicos com educação, para atingir os patamares propostos, deveriam atingir em dez anos 8\% do PIB. Nesse mesmo número está um artigo de Ivan C. Almeida (2001) trabalhando indicadores de gasto com educação no período de 1994 a 1999, em série histórica, por nível de ensino e por dependência administrativa, trabalhados com metodologia desenvolvida pelo Ipea. Em outra direção, cabe citar o artigo de Oliveira (2001) que desenvolveu estudo para avaliar os custos e benefícios de programas para regularização do fluxo escolar no ensino fundamental, trabalhando dados diversos, inclusive dos programas de aceleração, levantando as implicações para as políticas públicas.

A questão da responsabilidade dos municípios em relação à educação vem ocupando espaço nos trabalhos recentes, sobretudo com análises financeiras e de eficácia do Fundef, o que exige tratamento de dados quantitativos de variadas naturezas. Podemos citar aqui os trabalhos de Monlevade; Ferreira (1997); Guimarães (1999; 2000); Verhine (1999; 2000); Castro (1998); Pinto (2002). Ampliando o escopo dessas discussões, recentemente Martins; Perez
(2002) finalizaram trabalho sobre o processo de municipalização no estado de São Paulo, estudando, além de questões do Fundo, mudanças institucionais e os atores escolares, tentando verificar "se o novo desenho institucional configurado pelo processo de municipalização em curso democratizou a gestão da rede de escolas, tornando mais equânime a cobertura dos serviços educacionais, ou não" (Martins; Perez, 2002, p. 3); o trabalho de campo combinou dados quantitativos com coletas qualitativas, intercruzando inferências. Trabalharam com distribuição de matrículas numa seqüência de seis anos, analisando a municipalização por ano, porte do município, por regiões administrativas, pelo partido do prefeito, forma de municipalização, forma de contribuição para o Fundef. Constata-se uma heterogeneidade muito grande segundo subconjuntos de fatores intervenientes no processo de implementação dos sistemas municipais, e, com os estudos de caso realizados, mostram que de um lado

a mudança de lócus de negociação - da esfera estadual para a esfera municipal - atingiu as reivindicações e/ou expectativas dos docentes, acentuando ou (re)normatizando os conflitos entre os pares e entre estes e o novo centro do poder: a Secretaria Municipal de Educação. De outra parte, permitiu que os professores realizassem uma (re)leitura do próprio conjunto normativo-legal, possibilitando a construção de uma aprendizagem mais do que pedagógica, política, pois estes se viram na contingência de negociar em bases diferenciadas daquelas praticadas até então, possibilitadas pela proximidade do centro de poder. No entanto, nem todas as escolas municipalizadas encontraram caminhos de construção de seus próprios projetos, tendo em vista que os problemas provocados pelo convênio no que tange à situação funcional, atingiram a própria possibilidade de exercício da profissão. A emergência e consolidação de formas mais plausíveis de gestão descentralizada da escola pública dependerão do grau de maturidade política das instâncias e dos atores 
envolvidos nesse processo que será tanto maior, quanto maiores forem as chances de se exercitar a democracia como prática e não como conceito. (Martins; Perez, 2002, p. 109-110)

\section{Fatores sociais e educação}

As preocupações com as questões sociais e suas relações com a educação tornamse mais explícitas no final da década de 1970 e inícios de 1980. Gouveia (1980, p. 3-30) publica então amplo estudo sobre origem social, escolaridade e ocupação. Seu pano de fundo teórico é a determinação social da extensão da escolaridade, considerando ocupação do pai, sexo, idade, região (Nordeste/São Paulo), posições associadas a diferentes graus de escolaridade, participação na PEA (População Economicamente Ativa). Utilizando-se de indicadores e de testes de significância (qui-quadrado) vai entretecendo um panorama relativamente detalhado sobre as relações entre estes fatores e a escolaridade. Em conclusão afirma que,

se por um lado, a origem familiar condiciona a extensão da escolaridade do indivíduo, de outro, esta pode modificar o destino ocupacional comumente associado àquela mesma origem. A vantagem da escolaridade depende, porém, de certas circunstâncias, relacionadas em parte com transformações históricas que a todos os indivíduos de alguma forma atingem... Assim, o "efeito" de um curso "não se faz sentir da mesma maneira entre pessoas que provenham de origens diversas.

Não só este trabalho mas, vários outros de Joly Gouveia, influenciaram as reflexões e outras pesquisas de toda uma geração de pesquisadores na sociologia da educação.

Estudo de Lia Rosenberg publicado como livro (1984), sob o título Educação e desigualdade social, procurou analisar as relações entre origem social e rendimento escolar na rede pública de ensino fundamental, levando em conta algumas características das esco- las onde os alunos estudavam. Preocupa-se também com os fatores intra-escolares, ainda pouco estudados. A pesquisa foi amostral, por estratificação proporcional, integralizando 7.111 alunos. Coletou dados sobre idade, sexo, naturalidade, repetência anterior, inserção no mercado de trabalho, série, turno, rendimento escolar dos alunos. Utilizou dados para caracterização socioeconômica das famílias desses alunos compreendendo renda familiar mensal, renda per capita mensal, escolaridade do chefe de família e classificação na escala Azzi-Marchi. Trabalhou com tabelas cruzadas e fez testes de significância estatística. Mostrou que, quanto mais baixa a origem social do aluno, mais baixas as notas obtidas e mais altas as porcentagens de repetência, especialmente nas séries iniciais; que existe uma associação entre repetência anterior e uma nova repetência; mantida constante a origem social, mostra que a duração da jornada e outras condições da escola mantêm forte relação positiva com o rendimento; e, que a influência dos fatores intra-escolares na determinação do rendimento escolar é maior para os alunos de origem social mais baixa. Levanta a questão de que se fatores sociais externos interferem no desempenho escolar, este também é fortemente determinado por fatores intra-escolares. Há um processo de seletividade social em curso no interior das escolas. Mas considera que "o conflito e as contradições tanto no interior da escola como na sua relação com o social constituem o terreno para semear a inovação”. Esse trabalho com amostra ampla criou condições para a discussão do papel dos fatores intra-escolares na aprendizagem dos alunos, ampliando as perspectivas dos estudos de caso, muito situados e delimitados a uma sala de aula, a uma escola. 0 estudo de Lia Rosenberg, com ampla amostra, deu base para uma discussão em nível de sistema e da cultura educacional mais geral. Velloso (1984) estudou a questão da relação distribuição de renda $x$ educação $x$ políticas de Estado com base em hipóteses sugeridas por estudos econômicos e sociológi- 
cos. Trabalhou com um modelo de regressão múltipla, aplicado a dados de uma amostra de trabalhadores do sexo masculino, no setor urbano, que perceberam algum rendimento (a fonte foi o Censo Demográfico do Brasil). Estudou com esses dados as variações quanto à desigualdade de renda em função da alteração da distribuição de educação de 1960 a 1980, e quanto às taxas de retorno da educação. Os resultados levam à conclusão de que "contrapondo-se à crença na suficiência do papel redistributivo da educação está a evidência relativa aos efeitos da política econômica do Estado no aumento da desigualdade social" (Velloso, 1984, p. 281). Ou seja, a desigualdade de renda não diminui necessariamente com mudanças na distribuição da educação ou com o crescimento econômico nas nações subdesenvolvidas.

\section{Os jovens e a educação}

Em meados da década de 1980-90 despontam com maior força discussões sobre as questões ligadas aos jovens na dinâmica social e educacional. Madeira (1986) publica à época, estudo sobre os jovens e as mudanças estruturais, a partir de indicadores de vários tipos que tratam da inserção no trabalho de jovens, segundo sexo, setor da economia, tipo de ocupação, rendimento mensal, horas trabalhadas, situação domiciliar, situação econômica da família, cruzando com escolaridade (nível e anos de estudo). Algumas interpretações que avança dão conta da incompatibilidade do nível de crescimento e modernização de setores básicos da economia e o "descalabro" da situação educacional da população jovem brasileira, dentre outras constatações, por exemplo que na década anterior ao estudo, o que aumentou em ritmo mais acelerado foi a escolaridade da população jovem trabalhadora, a parcela que combina cotidianamente escola e trabalho.

Em outros termos, o que os dados estão evidenciando é que ao longo da década a escolaridade tornou-se uma credencial da maior importância, já que há uma clara tendência a que os níveis de escolaridade de adolescentes e jovens na PEA (população economicamente ativa) sejam mais elevados quando comparados com aqueles que estão fora da PEA. (Madeira, 1986, p. 26)

Em trabalho mais recente, Bercovich, Madeira; Torres pesquisaram "quantitativa e espacialmente as informações recentes relativas à situação demográfica, de trabalho e escolaridade dos adolescentes (1997)". Mostram onde estão, quantos são e quantos serão (estimativas), sua situação no trabalho por ramos de atividade - a partir do dado da PNAD em 1995 segundo o qual 56,6\% dos adolescentes eram econômicamente ativos -, sua situação escolar e a relação escola/trabalho/família. 0 panorama traçado sobre os adolescentes no Brasil só foi possivel por contar-se com dados numéricos e por uma escolha criteriosa de metodologia comparativa e multivariada que permitiu um quadro sintese provocativo. De um lado vê-se que não há como desconsiderar as diferenças regionais, e de outro observa-se que dinamicamente avançam apenas um pouco os níveis educacionais de adolescentes, mas diminui sua taxa de atividade, o que leva a constatar que "a dificuldade de inserção no mercado de trabalho tem produzido muito mais, como vimos, a perigosa inatividade total dos jovens do que facilidades para o avanço na escolaridade”.

\section{Avaliação Educacional}

É no campo dos estudos de avaliação educacional, mais especialmente nos estudos de rendimento escolar em nível de sistemas ou sub-sistemas, que se encontra a maioria dos estudos de cunho quantitativo nos últimos dez anos. É também nessa área que modelos de análise mais complexos vêm sendo utilizados: modelos da "teoria da reposta ao item", modelos de análise hierárquica, estudos de relações multivariadas, uso da teoria dos valores agregados, testes de componentes de variância diver- 
sos, entre outros. Algumas referências são os estudos de Vianna (1989) analisando o desempenho de alunos de escolas públicas em cidades de grande porte; Ribeiro (1991) sobre "A pedagogia da repetência”; Fletcher (1991) estudando o perfil cognitivo da população brasileira; Vianna (1991) trabalhando com dados de rendimento escolar de alunos do último ano do ensino médio; Neubauer, Davis; Espósito (1996) apresentando análises sobre o processo de inovações no ciclo básico e seus impactos sobre a situação de ensino, com análise longitudinal; Taurino (1997) pesquisando os conceitos de norma e critério de desempenho como parâmetros para avaliação de programas; Costa (1999) avaliando os impactos sociais de uma política educacional democrática; Valle (2000) apresentando a Teoria da Resposta ao item e aplicações em estudos avaliativos, sobretudo sobre comparações longitunais; Barbosa; Fernandes (2000) trabalhando modelo multinível aplicado a dados variados de avaliação educacional, Davis; Espósito; Nunes (2000) trabalhando o modelo de avaliação do Saresp e seus resultados, com estudo de significação de fatores intervenientes; Soares; Alves; Oliveira (2001) pesquisando o efeito de escolas de nível médio no vestibular da UFMG numa seqüência de anos; Fernandes; Natenzon (2003) estudando a evolução recente do rendimento escolar das crianças brasileiras através de uma reavaliação dos dados do Saeb; Klein (2003) discutindo o emprego da Teoria da Resposta ao Item no Saeb; Sztajn, Bonamino; Franco (2003) analisando a formação docente a partir dos levantamentos sucessivos do Saeb, com constructos elaborados especificamente para esta análise.

Cada um desses estudos traz informações e interpretações relevantes sobre aspectos diversificados e críticos da situação educacional, social e de aprendizagem de grandes camadas da população brasileira, levantando questões tanto sobre políticas como sobre ensino-aprendizagem, além de visões sobre aspectos de impacto social da educação.

\section{Temas variados/estudos amostrais menores}

Neste tópico lembramos de trabalhos com foco mais restrito, alguns de natureza quase-experimental, que utilizaram escalas de medida de diversas naturezas e/ou modelos de análise mais sofisticados, para além de médias e porcentagens, buscando modelos inferenciais, com testes de significância, análises de variância, análises de regressão múltipla, análises fatoriais, etc. Foram mais freqüentes nos anos 1970 até meados de 1980, sendo raríssimos na década de 1990. Citamos, entre vários, o clássico estudo de Poppovic; Espósito; Cruz (1973) criando uma metodologia para estudo de marginalização cultural, chegando a um complexo índice de referência, estudando-se, então, características psicológicas de adolescentes culturalmente marginalizados. Os dados analisados mostraram que "assim como o aluno culturalmente marginalizado não está preparado para a escola existente, também a escola não está preparada para atender a esse aluno" (p. 43), completando que, o fator "escola" completaria a direção a ser dada às pesquisas sobre margi-nalização cultural, as quais deveriam conter três aspectos fundamentais - os fatores ambientais atuantes, o aluno com suas características e a escola.

Para se ter uma idéia do leque de temas tratados, com as técnicas de análise destacadas acima, citamos como exemplo, os estudos de: Gatti; Goldberg (1974) analisando impacto de uma modalidade didática no desenvolvimento do comportamento científico em adolescentes; Barroso; Mello; Faria (1978) quanto à influência de características do aluno na avaliação do seu desempenho; Medeiros, Santarosa; Lewin (1979) estudando o papel do rádio no treinamento de professores; Silva (1980) analisando a questão da responsabilidade pelo sucesso e fracasso escolar em crianças; Alencar; Rodrigues (1980) buscando compreender as causas de satisfação e insatisfação entre professores do ensino de primeiro grau; Victoria; Martines (1982) estudando numa amostra de 500 crianças de $1^{\text {a }}$ 
série de $1^{\circ}$ grau a relação entre fatores socioeconômicos, estado nutricional e rendimento escolar; Carraher; Rego (1984) sobre desenvolvimento cognitivo e alfabetização; Freitag (2000) com um estudo sobre os efeitos de diferentes métodos de alfabetização sobre a psicogênese infantil e sobre o rendimento escolar; e Leite (1993) com um estudo sobre a passagem para a $5^{\text {a }}$ série. Nesse trabalho o autor teve por objetivo avaliar o repertório de alunos da $4^{\text {a }}$ série, introduzir programas de revisão e propor a continuidade do trabalho na $5^{\text {a }}$ série, tendo mostrado, a partir da análise dos resultados, que houve progressos relevantes no desempenho acadêmico dos alunos, discutindo-se as dificuldades específicas intra-escolares encontradas.

\section{Conclusão}

Estas análises, a partir de dados quantificados, contextualizadas por perspectivas teóricas, com escolhas metodológicas cuidadosas, trazem subsídios concretos para a compreensão de fenômenos educacionais indo além dos casuísmos e contribuindo para a produção/enfrentamento de políticas educacionais, para planejamento, administração/gestão da educação, podendo ainda orientar ações pedagógicas de cunho mais geral ou específico. Permitem ainda desmistificar representações, preconceitos, "achômetros", sobre fenômenos educacionais, construídos apenas a partir do senso comum do cotidiano, ou do marketing.

Lembramos que muito se discute sobre a qualidade dos dados estatísticos, das grandes bases, como os Censos e outros, sendo esta questão muito antiga. Não há como deixar de lado o problema da qualidade dos dados dessas bases, sendo que vários autores se debruçaram sobre o assunto apresentando os limites e possibilidades das mesmas. Porém, é inegável que essa qualidade melhorou, e muito, a partir das discussões e sugestões propostas por vários pesquisadores e demógrafos. Também é inegável que sem dados de natureza quantitativa muitas questões sociais/educacionais não poderiam ser dimensionadas, equacionadas e compreendidas, algumas não seriam mesmo levantadas. Cabe estar atentos, também, ao fato de que os processos necessários à quantificação (criação de medidas, de categorias, imposições formais, etc.) podem levar a mistificações do fenômeno, pelo que não se pode deixar de ter domínio sobre estes condicionantes e levá-los em conta, como ainda não se pode deixar de trabalhar com apoio de sólido referencial teórico transcendendo a essas modelagens, permitindo a visão clara dos limites desses estudos.

Mesmo concordando com a afirmação de Popkewitz (2001) de que as "estatísticas participam da lógica sedutora da ciência numa idade de racionalidade e razão" (p. 114), lembramos que as metodologias qualitativas também são empregadas dentro dessa racionalidade. Cabem, então, distinções de foro filosófico ou teórico-interpretativo na atribuição de significação a números e tratamentos, sejam estes quantitativos ou qualitativos. Muito já se lembrou a afirmação de Karl Marx no Prefácio à primeira edição de $O$ Capital em que critica fortemente a consistência das estatísticas sociais da Alemanha e do resto do continente europeu ocidental, em relação com o que vira na Inglaterra, à época, mais de século atrás. Mesmo com a pertinente crítica, não deixou de utilizar essas estatísticas afirmando: "Ainda assim, levanta o véu o bastante para deixar entrever atrás do mesmo uma cabeça de Medusa" (Marx, 1983, v.1, p. 12-13).

Quanto aos diferentes registros de escolarização, Ferrari (2002, p. 44) comenta que

a área de educação poderia dar mais atenção às potencialidades, aos limites e aos métodos relacionados com o uso de dados originados de fontes como os censos, as PNADs e os registros escolares. Temo que, com o argumento de livrar-se do quantitativismo e dos problemas relacionados com a utilização das estatísticas educacionais, tenha-se acabado por jogar fora a criança junto com a água do banho. Se assim foi, talvez se possa ainda recuperá-la."

0 mesmo comentário pode ser aplicado quanto ao emprego de quantificação em trabalhos de escopo mais específico, em estudos de dimensão menor. 


\section{Referências bibliográficas}

ALENCAR, E. M. L. S. de; RODRIGUES, C. J. S. Causas de satisfação e de insatisfação entre professores do ensino de $1^{\circ} \mathrm{grau}$. Revista Brasileira de Estudos Pedagógicos, Brasília, v. 63, n. 146, p. 391-402, jan./abr. 1980.

ALMEIDA, I. C. Gastos com educação no período de 1994 a 1999. Revista Brasileira de Estudos Pedagógicos, Brasília, v. 82, n. 200/202, p. 137-198, jan./dez. 2001.

BARBOSA, M. E. F.; FERNANDES, C. Modelo multinível: uma aplicação a dados de avaliação educacional. Estudos em Avaliação Educacional, São Paulo, n. 22, p. 135-154, jul./dez. 2000.

BARRETTO, E. S. de S. et al. Ensino de $1^{\circ}$ e $2^{\circ}$ graus: intenção e realidade. Cadernos de Pesquisa, São Paulo, n. 30, p. 21-40, set. 1979.

BARROSO, C. L. de M.; MELLO, G. N.; FARIA, A. L. G. de. Influência de características do aluno na avaliação do seu desempenho. Cadernos de Pesquisa, São Paulo, n. 26, p. 61-80, set. 1978.

BERCOVICH, A. M.; MADEIRA, F. R.; TORRES, H. G. Mapeando a situação do adolescente no Brasil, Belo Horizonte, 1997.

BONAMINO, A.; COSCARELLI, C.; FRANCO, C. Avaliação e letramento: concepções de aluno letrado subjacentes ao SAEB e ao PISA. Educação \& Sociedade, Campinas, v. 23, n. 81, p. 91-113, dez. 2002.

CARRAHER, T. N.; REGO, L. L. B. Desenvolvimento cognitivo e alfabetização. Revista Brasileira de Estudos Pedagógicos, Brasília, v. 65, n. 149, p. 38-55, jan./abr. 1984.

CARVALHO, J. C. B. de. Diagnóstico educacional dos municípios periféricos da região metropolitana do Rio de Janeiro. Revista Brasileira de Estudos Pedagógicos, Brasília, v. 64, n. 148, p. 165-190, set./dez. 1983.

CASTRO, J. A. de. O fundo de manutenção e desenvolvimento do ensino e valorização do magistério FUNDEF e seu impacto no financiamento do ensino fundamental. Brasília: IPEA, 1998. 46p.

COSTA, M. da. Avaliando impactos sociais de uma política educacional democrática. Estudos em Avaliação Educacional, São Paulo, n. 19, p. 25-55, jan./jun. 1999.

DAVIS, C.; ESPÓSITO, Y. L.; NUNES, M. M. R. Sistema de avaliação do rendimento escolar: o modelo adotado pelo estado de São Paulo. Revista Brasileira de Educação, São Paulo, n. 13, p. 25-53, jan./abr. 2000.

DI DIO, R. A. T. A pesquisa educacional no Brasil. Revista Brasileira de Estudos Pedagógicos, Rio de Janeiro, v. 60, n. 136, p. 461629, out./dez. 1974.

FALCÃO, J. T. da R.; RÉGNIER, J. Sobre os métodos quantitativos na pesquisa em ciências humanas: riscos e benefícios para 0 pesquisador. Revista Brasileira de Estudos Pedagógicos, Brasília, v. 81, n. 198, p. 229-243, maio./ago. 2000.

FERNANDES, R.; NATENZON, P. E. A evolução recente do rendimento escolar das crianças brasileiras: uma realização dos dados do Saeb. Estudos em Avaliação Educacional, São Paulo, n. 28, p. 3-22, jul./dez. 2003.

FERRARI, A. R. Analfabetismo e níveis de letramento no Brasil: o que dizem os censos? Educação \& Sociedade, Campinas, v. 23, n. 81, p. 21-47, dez. 2002. 1985.

. Analfabetismo no Brasil: tendência secular e avaliações recentes. Cadernos de Pesquisa, São Paulo, n. 52, p. 35-49, fev.

Evolução da educação pré-escolar no Brasil no período de 1968 a 1986. Revista Brasileira de Estudos Pedagógicos, Brasília, v. 69, n. 161, p. 55-74, jan./abr. 1988.

Utilização das estatísticas educacionais dos censos demográficos e dos registros escolares: uma tipologia de análises. Educação e Realidade, Porto Alegre, v. 4, n. 2, p. 253-266, jul./set. 1979. 
FLETCHER, P. R. Avaliação do perfil da população brasileira. Estudos em Avaliação Educacional, São Paulo, n. 4, p. 27-64, jul./dez. 1991.

FLETCHER, P. R.; RIBEIRO, S. C. Modeling education system performance with demographic data: na introdution to the PROFLUXO model. Brasília: IPEA, 1989. Mimeografado.

FRANCO, M. L. P. B.; ZIBAS, D. M. L. O ensino médio no Brasil neste final do século: uma análise de indicadores. São Paulo: FCC/ DPE, 1999. (Textos FCC, n. 18)

FREITAG, B. Alfabetização e linguagem. Revista Brasileira de Estudos Pedagógicos, Brasília, v. 70, n. 166, p. 317-345, set./dez. 2000.

GATTI, B. A.; GOLDBERG, M. A. A. Influência dos "kits": os cientistas no desenvolvimento do comportamento científico em adolescentes. Cadernos de Pesquisa, São Paulo, n. 10, p. 13-23, ago. 1974.

GOMES NETTO, J. B. F. et al. Investimentos auto-financiáveis em educação. Cadernos de Pesquisa, São Paulo, n. 85, p. 11-25, maio 1993.

GOUVEIA, A. J. Origem social, escolaridade e ocupação. Cadernos de Pesquisa, São Paulo, n. 32, p. 3-30, fev. 1980.

GUIMARÃES, J. L. O Impacto do FUNDEF para a educação infantil: conjecturas a partir da sua implantação no estado de São Paulo. In: MACHADO, M. L. A. (Org.) Educação infantil em tempos de LDB, São Paulo, 2000. p.75-91. (Textos FCC, n. 19).

. As vulnerabilidades do FUNDEF: conjecturas a partir da sua implantação no estado de São Paulo. In: BICUDO, M. A. V.; SILVA JR., C. da (Org.) Formação do educador e avaliação educacional: organização da escola e do trabalho pedagógico. São Paulo: UNESP, 1999. v. 3, p. 53-67.

KLEIN, R. Utilização da teoria da resposta ao item do Sistema Nacional de Avaliação da Educação Básica (SAEB). Ensaio, Rio de Janeiro, v. 11, n. 40, p. 283-296, jul./set. 2003.

LEITE, S. A. da S. A passagem para a 5a série: um projeto de intervenção. Cadernos de Pesquisa, São Paulo, n. 84, p. 31-42, fev. 1993.

MADEIRA, F. R. Os jovens e as mudanças estruturais na década de 70: questionando pressupostos e sugerindo pistas. Cadernos de Pesquisa, São Paulo, n. 58, p. 15-48, ago. 1986.

MARTINS, A. M.; PEREZ, J. R. R. o processo de municipalização no estado de São Paulo: mudanças institucionais e atores escolares. São Paulo: FCC, 2002. (Relatório Técnico)

MARX, K. O Capital. São Paulo: Abril Cultural, 1983. v.1.

MEDEIROS, M. F. de; SANTAROSA, L. M. C.; LEWIN, Z. G. 0 papel do rádio no treinamento de professores. Educação e Realidade, Porto Alegre, v. 4, p. 7-33, jan./jun. 1979.

MELCHIOR, J. C. de A. A aplicação de recursos financeiros em educação. Cadernos de Pesquisa, São Paulo, n. 25, p. 5-16, jun. 1978.

. Financiamento da educação no Brasil numa perspectiva democrática. Cadernos de Pesquisa, São Paulo, n. 34, p. 39-83, ago. 1980.

MONVELADE, J.; FERREIRA, E. S. O FUNDEF e seus pecados capitais: análise do fundo, suas implicações positivas e negativas e estratégias de superação de seus limites. Ceilândia, DF: Idea, 1997. 96p.

NEUBAUER, R.; ESPÓSITO, Y. L.; DAVIS, C. Avaliação do processo de inovações no ciclo básico e seu impacto sobre a situação de ensino-aprendizagem na região metropolitana de São Paulo. Estudos em Avaliação Educacional, São Paulo, n. 13, p. 35-64, jan./ jun. 1996. 
OLIVEIRA, J. B. A. Custos e benefícios de programas para regularizar o fluxo escolar no ensino fundamental: novas evidências. Ensaio, Rio de Janeiro, v. 9, n. 32, p. 305-342, jul./set. 2001.

PARO, V. H. 0 custo do ensino público no estado de São Paulo: estudo de custo/aluno na rede estadual de primeiro e segundo graus. Cadernos de Pesquisa, São Paulo, n. 43, p. 3-29, ago. 1982.

PINTO, J. M. de R. Financiamento da educação no Brasil: um balanço do governo FHC (1995-2002). Educação \& Sociedade, Campinas, v.3, n. 80, p. 109-136, set. 2002.

PINTO, J. M. de R. et al. Um olhar sobre os indicadores de analfabetismo no Brasil. Revista Brasileira de Estudos Pedagógicos, Brasília, v. 81, n. 199, p. 511-524, set./dez. 2000.

POPKEWITZ, T. Estatísticas educacionais como um sistema de razão: relações entre governos da educação e inclusão e exclusão sociais. Educação \& Sociedade, Campinas, n. 75, p. 111-148, ago. 2001.

POPPOVIC, A. M.; ESPOSITO, Y. L.; CRUZ, L. M. C. Marginalização cultural: uma metodologia para seu estudo. Cadernos de Pesquisa, São Paulo, n. 7, p. 5-60, jun. 1973.

RELATÓRIO do grupo de trabalho sobre financiamento da educação. Revista Brasileira de Estudos Pedagógicos, Brasília, v.82. n. 200/202, p. 117-136, jan./dez. 2001.

RIBEIRO, S. C. A educação e a inserção do Brasil na modernidade. Cadernos de Pesquisa, São Paulo, n. 84, p. 3-96, fev. 1993. . A pedagogia da repetência. Estudos em Avaliação Educacional, São Paulo, n. 4, p. 73-86, jul./dez. 1991.

RIBEIRO, V. M. M. Alfabetismo e atitudes: pesquisa junto a jovens e adultos paulistanos. Revista Brasileira de Educação, São Paulo, n. 9, p. 5-15, set./dez. 1998.

(Org.). Letramento no Brasil. São Paulo: Global; Ação Educativa; Instituto Paulo Montenegro, 2003.

RIBEIRO, V. M.; VÓVIO, C. L.; MOURA, M. P. Letramento no Brasil: alguns resultados do indicador nacional de analfabetismo funcional. Educação \& Sociedade, Campinas, v. 23, n. 81, p. 49-70, dez. 2002.

ROSEMBERG, F. 0 a 6: desencontro de estatísticas e atendimento. Cadernos de Pesquisa, São Paulo , n. 71, p. 36-48, nov. 1989. . Avaliação de programas, indicadores e projetos em educação infantil. Revista Brasileira de Educação, São Paulo, n. 16, p. 19-26, jan./abr. 2001. . Educação infantil, classe, raça e gênero. Cadernos de Pesquisa, São Paulo, n. 96, p. 58-65, fev. 1996. 1992. . A educação pré-escolar brasileira durante os governos militares. Cadernos de Pesquisa, São Paulo, n. 82, p. 21-30, ago.

. 0 estado dos dados para avaliar políticas de educação infantil. Estudos em Avaliação Educacional, São Paulo, n. 20, p. 5-57, jul./dez. 1999.

. Expansão da educação infantil e processos de exclusão. Cadernos de Pesquisa, São Paulo, n. 107, p. 7-40, jul. 1999.

- Indicadores sócio-demográficos de crianças de 0 a 6 anos no Brasil. Revista Brasileira de Crescimento e Desenvolvimento Humano, São Paulo, v. 1, n. 1, p. 99-109, jan./jun. 1991.

. Instrução, rendimento, discriminação racial e de gênero. Revista Brasileira de Estudos Pedagógicos, Brasília, v. 68, n. 159, p. 324-355, maio/ago. 1987.

ROSENBERG, L. Educação e desigualdade social. São Paulo: Loyola, 1984. (Coleção Espaço)

SOARES, J. F.; ALVES, M. T. G.; OLIVEIRA, R. M. de. 0 efeito de 248 escolas de nível médio no vestibular da UFMG nos anos de 1998, 1999 e 2000. Estudos em Avaliação Educacional, São Paulo, n. 24, p. 69-118, jul./dez. 2001. 
SILVA, T. R. N. A responsabilidade pelo sucesso e fracasso escolar em crianças. Cadernos de Pesquisa, São Paulo, n. 32, p. 3144, fev. 1980.

SOLARI, A. Indicadores em educação. In: MENDES, C. et al. O outro desenvolvimento. Rio de Janeiro, 1963. p. 61-97.

STAJN, P.; BONAMINO, A.; FRANCO, C. Formação docente nos surveys de avaliação educacional. Cadernos de Pesquisa, São Paulo, n. 118, p. 11-39, mar. 2003.

TAURINO, M. do S. Norma e critério de desempenho como parâmetros da avaliação da aprendizagem. Estudos em Avaliação Educacional, São Paulo, n. 15, p. 135-198, jan./jun. 1997.

VALLE, R. da C. Teoria da resposta ao item. Estudos em Avaliação Educacional, São Paulo, n. 21, p. 7-92, jan./jun. 2000.

VELLOSO, J. Distribuição de renda: educação e políticas de Estado. In: LEVIN, H. M. Educação e desigualdade no Brasil. Rio de Janeiro: Vozes, 1984. p. 255-289.

0 financiamento da educação na transição democrática. Em Aberto, Brasília, v. 4, n. 25, p. 29-38, jan./mar. 1985.

. Financiamento das políticas públicas: a educação. Revista da ANDE, São Paulo, v. 6, n. 12, p. 27-32, 1987a.

Política educacional e recursos para o ensino: o salário-educação e a Universidade Federal. Cadernos de Pesquisa, São Paulo, n. 61, p. 3-29, maio. 1987b.

Universidade na América Latina: rumos do financiamento. Cadernos de Pesquisa, São Paulo, n. 110, p. 39-66, jul. 2000.

VELLOSO, J. et al. Financiamento da educação no Brasil. In: CONFERÊNCIA BRASILEIRA DE EDUCAÇÃO, 6., 1992, Campinas. Anais... Campinas: Papirus, 1992.

VERHINE, R. E. O FUNDEF: suas implicações para a descentralização do ensino e o financiamento da educação no Brasil. Revista da FAEEBA, Salvador, v. 8, n.12, p. 131-151, jul./dez. 1999.

Um experimento chamado FUNDEF: uma análise do seu desempenho no cenário nacional e no contexto da Bahia. Educação Brasileira, Brasília, v. 22, n. 45, p. 121-146, jul./dez. 2000.

VIANNA, H. M. Avaliação do rendimento de alunos de escolas do $1^{\circ}$ grau da rede pública: um estudo em 20 cidades. Educação e Seleção, São Paulo, n. 19, p. 33-98, jun. 1989.

. Avaliação do rendimento escolar de alunos da $3^{\mathrm{a}}$ série do $2^{\circ} \mathrm{grau}$ : subsídios para uma discussão. Estudos em Avaliação Educacional, São Paulo, n. 3, p. 71-102, jan./jun. 1991.

VICTORIA, C. G.; MARTINES, J. C. Fatores sócio-econômicos, estado nutricional e rendimento escolar: um estudo em 500 crianças de primeira série. Cadernos de Pesquisa, São Paulo, n. 41, p. 38-48, maio 1982.

Recebido em 04.03.04

Aprovado em 03.05.04

Bernadete A. Gatti é doutora em Psicologia (Educação) pela Universidade de Paris VII, pós-doutorados nas universidades de Montreal (Canadá) e da Pensilvânia (USA). Coordenadora do Departamento de Pesquisas Educacionais da Fundação Carlos Chagas e docente do Programa de Pós-Graduação em Psicologia da Educação da PUC-SP. 